\title{
Different Flooding Behaviors Due to Varied Urbanization Levels within River Basin: A Case Study from the Xiang River Basin, China
}

\author{
Juan Du ${ }^{1,2,3,4} \cdot$ Linlin Cheng $^{1} \cdot$ Qiang Zhang ${ }^{1,2,4} \cdot$ Yumeng Yang $^{1}$ • \\ Wei $X u^{1,2,4}$
}

Published online: 15 November 2018

(C) The Author(s) 2018

\begin{abstract}
Booming urbanization due to a fast-growing population results in more impervious areas, less infiltration, and hence greater flood peak and runoff. Clear understanding of flood responses in regions with different levels and expansions of urbanization is of great importance for regional urban planning. In this study, comparison of flooding responses to urbanization processes in terms of flood peak and runoff volume in the upper, middle, and lower Xiang River Basin (XRB), China, was carried out using the Hydrologic Engineering Center-Hydrologic Modeling System (HEC-HMS) model. From 2005 to 2015, urbanization level and intensity were higher in the lower XRB compared to the upper and middle XRB, and the overall expansion rate of urban areas was $112.8 \%$. Modeling results by the HEC-HMS model indicate elevated flood peak discharges and volumes due to fast urbanization in the XRB from the 1980s to 2015. This rapid increase is particularly the case in the lower XRB. The study also revealed different hydrological responses of flood regimes - urbanization tends to have larger impacts on peak flood flow rather than on flood volume in the lower
\end{abstract}

Qiang Zhang

zhangq68@bnu.edu.cn

1 Key Laboratory of Environmental Change and Natural Disaster, Ministry of Education, Beijing Normal University, Beijing 100875, China

2 State Key Laboratory of Earth Surface Processes and Resource Ecology, Beijing Normal University, Beijing 100875, China

3 State Key Laboratory of Remote Sensing Science, Beijing Normal University, Beijing 100875, China

4 Academy of Disaster Reduction and Emergency Management, Faculty of Geographical Science, Beijing Normal University, Beijing 100875, China
$\mathrm{XRB}$, which further corroborated urbanization-induced intensifying flood processes in terms of peak flood flow. Urbanization has increasing impacts on flood volume from the upper to the lower XRB, which can be attributed to accumulated runoff down the river system. This study provides a reference for basin-wide land use and urban planning as well as flood hazard mitigation.

Keywords Flood volume - Flooding processes - HECHMS $\cdot$ Peak flood flow $\cdot$ Urbanization level $\cdot$ Xiang River Basin · China

\section{Introduction}

Urban areas are home to more than half of the global population, and this proportion is projected to be $60 \%$ by 2030 (United Nations, Department of Economic and Social Affairs, Population Division 2011). Numerous cities are growing in size at a phenomenal rate (Pathirana et al. 2014). Urbanization-driven land use change influences local hydrometeorology by modifying surface and boundary layer atmospheric properties (Ren et al. 2008; Zhong et al. 2015), which changes the urban microclimate and significantly affects urban flood processes (Muis et al. 2015). Land use and land cover (LULC) changes associated with urbanization also extensively affect hydrological processes by altering the partitioning of rainwater through the vegetation and soil into interception, infiltration, evaporation, surface runoff, and groundwater recharge (Warburton et al. 2012). At the basin scale, urbanization significantly modifies hydrological processes and potentially intensifies flooding processes (Shuster et al. 2005; Zhou et al. 2013). Urbanized watersheds, on average, lose $90 \%$ of storm rainwater to runoff, whereas nonurban, 
forested watersheds retain $25 \%$ of their rainwater (Sheng and Wilson 2009). It is well accepted that impacts of urbanization on hydrological processes can be attributed to increased impervious surface areas (Shuster et al. 2005; Miller et al. 2014; Du et al. 2015).

Recent studies evidenced altered hydrological responses within river catchments in coastal regions of China and in the world due to rapid urbanization (Aerts et al. 2014). Yin et al. (2016) analyzed the impacts of land subsidence on urban pluvial flooding in Shanghai and found that pluvial flash floods resulted in proportionate but nonlinear impacts on intraurban road inundation risks. Du et al. (2015) investigated the impact of rapid urban expansion on floods in the Longhua Basin, western Shenzhen, and found that peak discharge and flood volume increased by $140 \%$ and $162 \%$, respectively, over the past 30 years. Zhang et al. (2015) studied the effects of rapid urbanization-induced fluvial geomorphology changes on local flood frequency in Hangzhou, and showed that flood frequency increased as the fractal dimension of a river network decreased. Hydrological effects of urbanization are expected to be more complicated in inland river basins due to complex fluvial topography and spatially heterogeneous underlying surface features. Although urbanization-induced floods have been documented in a large number of case studies, most studies focused on models and/or analytical techniques (Elliott and Trowsdale 2007; Abdellatif et al. 2015) and meteorological driving factors (Zhou et al. 2018). Few reports are available that address different hydrological responses to urbanization across river basins due to different urbanization levels within a basin. But a detailed understanding of such responses is necessary for basinscale urban planning for and mitigation of flood hazards. This constitutes the major motivation of this study.

The Xiang River Basin (XRB) is located in the upper and middle Yangtze River Basin (Fig. 1). It runs through vast areas with various landforms and significant disparity in economic development. Therefore, different urbanization levels and processes exist across the XRB. The area is frequently stricken by storms and floods-29 floods occurred during the second half of the 20th century and about one flood event occurred every 1.7 years on average. Particularly, large flood events occurred in 1954, 1976, 1994, 1996, and 1998, with an average return period of 9.6 years (Du 2010). Moreover, recent years witnessed a higher frequency of storms and floods (Luo et al. 2013). Rapid urbanization in the XRB is expected to intensify flooding processes. In addition, due to regionally different economic development and urbanization processes, different flooding responses to urbanization are expected within the basin. Therefore, a closer look at different hydrological responses to different levels of urbanization and different urban expansions is needed in the study region. Meanwhile, this case study may provide a comparative reference point for similar studies in other river basins globally.

Hydrological models are widely employed to quantify the effects of LULC on hydrological processes at basin and even global scales (Du et al. 2012; Halwatura and Najim 2013; Miller et al. 2014; Li et al. 2016). The selection criteria of hydrological models depend on the purpose of the study and data availability. Previous studies have demonstrated the ability of the Hydrologic Engineering Center-Hydrologic Modeling System (HEC-HMS) to determine the effects of land use and/or climate changes on hydrologic changes in different catchments (Tripathi et al. 2014; Akter and Ahmed 2015; Du et al. 2015; Zope et al. 2016). Therefore, this study used the HEC-HMS model to evaluate impacts of inland urbanization on flooding in the three subcatchments with diverse degrees of urbanization in the XRB. The main objectives of the study are to: (1) analyze the flood processes and LULC changes between the 1980s, 2005, and 2015 across the basin; (2) investigate flood responses to different urbanization levels within different parts of the basin in terms of peak flood flow and flood volume; and (3) quantify the relationships between subcatchment attributes, LULC changes, and floods.

\section{The Study Region and Data}

The Xiang River, a major tributary of the Yangtze River, originates in the Haiyang Mountains in Guangxi Province and flows $844 \mathrm{~km}$ northward to Dongting Lake (Fig. 1), with a drainage area of $94,660 \mathrm{~km}^{2}$. The upper Xiang River is $234 \mathrm{~km}$ in length and is located in mountainous areas. The middle Xiang River is $290 \mathrm{~km}$ and is in a hilly area, and this part of the river is wider with terraces/mesas. The lower Xiang River is $320 \mathrm{~km}$ and runs through low hills and plains. The XRB is characterized by a subtropical humid monsoon climate with abundant rainfall. The average annual rainfall is $1400 \mathrm{~mm}$, and the average annual temperature is $17.6{ }^{\circ} \mathrm{C}$. The region is in Hunan Province and geomorphologically connects the Pearl River Delta and the Yangtze River coastal zones. It is an economically developed major industrial and agricultural area (Wang et al. 2008). The region's major cities are along the main stream of the Xiang River. Urban expansion of these major cities is fast and this growth is particularly the case for the Changsha-Zhuzhou-Xiangtan urban agglomeration (Liu et al. 2011). The XRB comprises $1736,000 \mathrm{hm}^{2}$ of farmland, which accounts for $52.7 \%$ of the area of Hunan Province.

In this study, hourly rainfall data were collected at 57 rain gauge stations covering the period from 2007 to 2012, and the rainfall data were provided by the China 


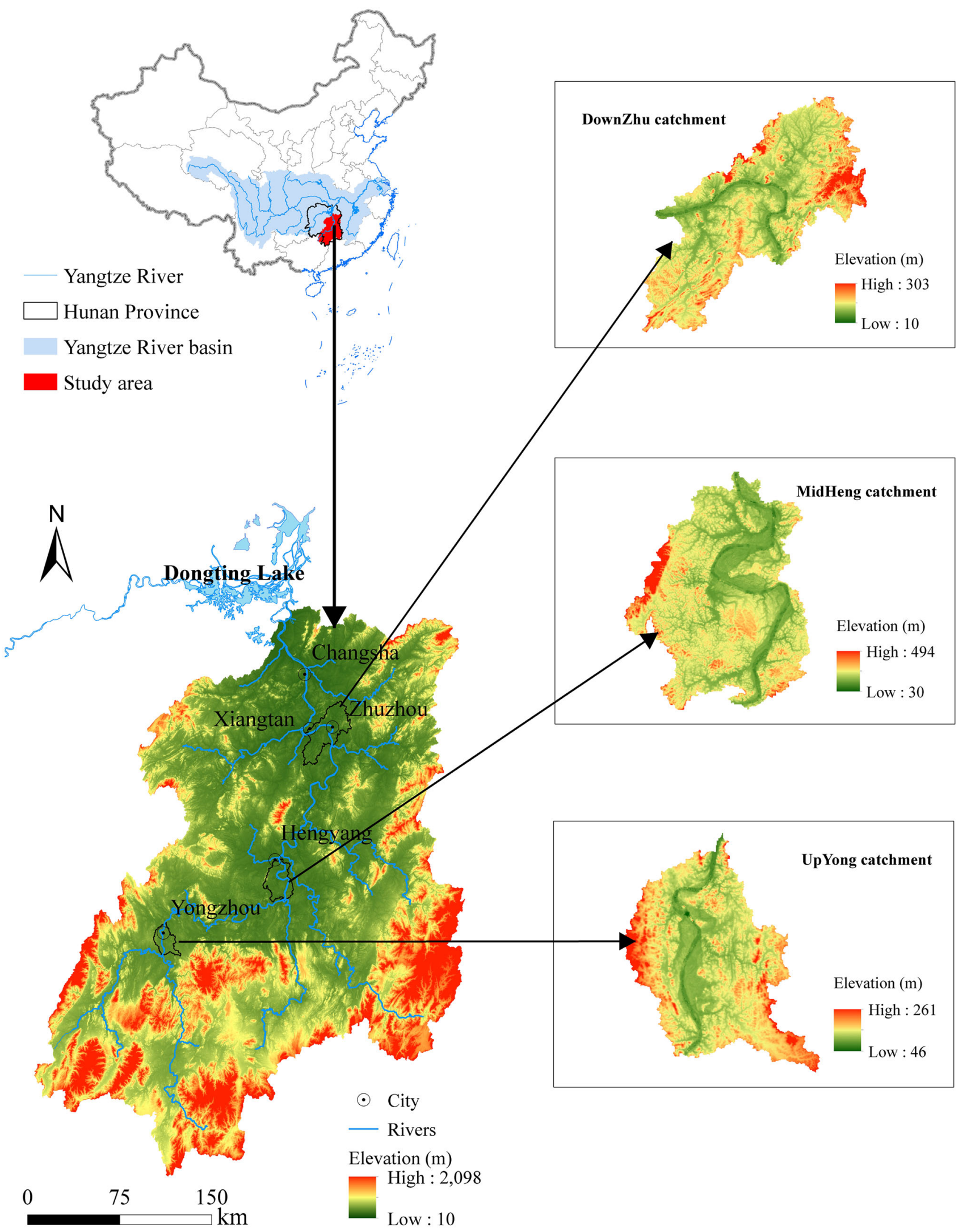

Fig. 1 Locations of the study area and major cities in the Xiang River Basin 
Meteorological Data Sharing Service System. ${ }^{1}$ The streamflow data from 2007 to 2012 were collected at the Xiangtan hydrological station, which is located at the outlet of the basin. The streamflow data were provided by the Hunan Hydrology and Water Resource Authority. The LULC data sets for the 1980s, 2005, 2010, and 2015 were collected from the Data Sharing Network of Earth System Science and the Institute of Geographic Science and Natural Resources Research, Chinese Academy of Sciences, ${ }^{2}$ and reclassified into cultivated land, forest, grassland, water bodies, artificial surfaces, and bare land.

Soil types of the study region were extracted from the Harmonized World Soil Database (v1.1) provided by the Cold and Arid Regions Environmental and Engineering Research Institute, Chinese Academy of Sciences $^{3}$ at a scale of 1:1,000,000. According to the rules of hydrologic soil group (HSG) classifications (A, B, C, and D) developed by the U.S. Natural Resource Conservation Service, HSGs represent moderate to slow infiltration rates when the soils are thoroughly wetted given that they are not protected by vegetation and have experienced long-duration storms (Feldman 2000). In this study, we used Table 1 to determine HSGs according to soil texture (Brakensiek and Rawls 1983). The main hydrologic soil group B covers $45.14 \%$ of the total area in the study region, followed by the D group that accounts for $29.89 \%$ of the total area of the region.

Landsat Thematic Mapper (TM) images with $30 \mathrm{~m}$ resolution for deriving imperviousness of urban areas were obtained from the Computer Network Information Center, Chinese Academy of Sciences ${ }^{4}$ for years 1988, 2005, 2010, and 2015.

\section{Hydrologic Engineering Center-Hydrologic Modeling System-Based Analysis Procedure}

This section details the hydrologic modeling and analysis procedure, including the HEC-HMS model; calculation of excess precipitation, direction runoff, baseflow, and channel routing; and model calibration and validation.

\subsection{Description of the Hydrologic Engineering Center-Hydrologic Modeling System Model}

The HEC-HMS model is a semi-distributed, event-scale hydrological model used to represent hydrological processes, and it is sensitive to land use change (Suriya and

\footnotetext{
$\overline{1} \mathrm{http} / / /$ data.cma.cn.

2 http://www.resdc.cn.

${ }^{3}$ http://westdc.westgis.ac.cn.

${ }^{4}$ http://www.gscloud.cn.
}

Table 1 Hydrologic soil groups by soil texture in the Xiang River Basin

\begin{tabular}{ll}
\hline HSG & Soil texture \\
\hline A & Sand, loamy sand, or sandy loam \\
B & Silt loam or loam \\
C & Sandy clay loam \\
D & Clay loam, silty clay loam, sandy clay, silty clay, or clay \\
\hline
\end{tabular}

Mudgal 2012; Zope et al. 2016). It divides an entire river basin into homogeneous subbasins based on the drainage area threshold defined in the model, which is not so elaborated compared with fully-distributed hydrological models. The HEC-HMS model takes into consideration changes in the underlying surface conditions of different sub-basins, and can have a great improvement in calculation efficiency. Moreover, the model focuses on the short-term flood events usually caused by rainstorms, thus snow melting and evapotranspiration are not considered. In this regard, a semi-distributed hydrological model is a better choice for the simulation of flood events in large-scale basins. In this study, HEC-HMS $v 4.2^{5}$ was employed to estimate direct runoff under different land use conditions. The HEC-HMS model includes the Basin Model, Meteorologic Model, Control Specification, and Time-Series Data Manager components. The Basin Model is formed by different hydrologic elements: reaches, subbasins, diversions, junctions, reservoirs, and sources and sinks. The Meteorologic Model is used to input rainfall data associated with each sub-basin. Rainfall values are calculated at the subbasin scale using the gauge weighting method based on rainfall observations by the 57 rain gauge stations in study area. The Control Specification component determines what time step to use and when simulations should start and stop. The Time-Series Data Manager includes the rainfall data and the observed discharge data. The Basin Model, Meteorologic Model, Control Specification, and Time-Series Data Manager components are combined to estimate excess precipitation, direct runoff, baseflow, and channel routing.

\subsection{Excess Precipitation: Soil Conservation Service Curve Number}

The Soil Conservation Service Curve Number (SCS-CN) is a function of cumulative precipitation, soil types, LULC, and antecedent moisture (USDA 2004). In this study, we used this method to estimate the excess precipitation:

\footnotetext{
$\overline{5}$ http://www.hec.usace.army.mil/software/hec-hms/downloads.aspx.
} 
$P_{e}=\frac{\left(P-I_{a}\right)^{2}}{P+S-I_{a}}$

where $P_{e}$ and $P$ are the accumulated excess precipitation and rainfall depth, respectively, at time $t, I_{a}$ is the initial loss, and $S$ is the potential maximum retention. An empirical linear relationship between $I_{a}$ and $S$ was developed by the SCS, as $I_{a}=0.2 S$. $S$ is determined using the following equation (SI units):

$S=\frac{25400}{C N}-254$

where $C N$ is the SCS curve number, which is estimated according to the characteristics of the watershed area, including soil type, land use, and the previous watershed moisture conditions. The value of $C N$ ranges from 100 for water bodies to 30 for highly permeable soils. $C N$ value is one of the parameters used to represent the urbanization level. To construct the $C N$ values of the basin, the land use and soil maps were overlaid using HEC-GeoHMS tools in ArcGIS. Table 2 is the $C N$ look up table used in this study, and it was based on both the standard table provided by the SCS report "Urban Hydrology for Small Watersheds" (TR-55) (Cronshey 1986) and the study of Yuan (2003) in Shenzhen, China.

Imperviousness, quantified by the impervious surface ratio (ISR) - the proportion of an area that is covered by impervious surfaces-is the other parameter used to reflect the urbanization level, and was obtained from Landsat TM images. Impervious surfaces can be represented by low and high albedo endmembers as follows.

$R_{\mathrm{imp}, b}=f_{\text {low }} R_{\text {low }, b}+f_{\text {high }} R_{\mathrm{high}, b}+e_{b}$

$R_{\mathrm{imp}, b}$ is the reflectance spectra of impervious surfaces for band $b$, and $f_{\text {low }}$ and $f_{\text {high }}$ are the fractions of low albedo and high albedo, respectively. $R_{\text {low }, b}$ and $R_{\text {high }, b}$ are the reflectance spectra of low albedo and high albedo for band $b$, and $e_{b}$ is the unmodeled residual. Associated with determining $R_{\text {imp }, b}$ is the requirement $f_{\text {low }}+f_{\text {high }}=1$ and $f_{\text {low }}, f_{\text {high }} \geq 0$ (Wu and Murray 2003).

Table 2 Curve numbers for hydrologic soil groups A, B, C, and D in the Xiang River Basin. Source Cronshey (1986) and Yuan (2003)

\begin{tabular}{lllll}
\hline LULC class & A & B & C & D \\
\hline Cultivated land & 67 & 78 & 85 & 89 \\
Forest & 30 & 55 & 70 & 77 \\
Grassland & 39 & 61 & 74 & 80 \\
Water & 98 & 98 & 98 & 98 \\
Artificial surfaces & 85 & 90 & 92 & 94 \\
Bare land & 72 & 82 & 88 & 90 \\
\hline
\end{tabular}

\subsection{Direct Runoff: Soil Conservation Service Unit Hydrograph}

The SCS Unit Hydrograph (SCS-UH) model (Feldman 2000) was applied to estimate direct runoff. The SCS-UH model is based on the average $\mathrm{UH}$ derived from gauged rainfall and runoff in a large number of small agricultural watersheds throughout the United States:

$U_{p}=C \frac{A}{T_{p}}$

$T_{p}=\frac{\Delta t}{2}+t_{\text {lag }}$

where $A$ is the watershed area, $C$ is the conservation constant (2.08 in the SI system), $U_{p}$ is the UH peak discharge, $T_{p}$ is the time of the UH peak, and $t_{l a g}$ is the basin lag time, that is, the time delay between observing the centroid of the mass of excess precipitation and the peak discharge of the UH. The key input parameter for this method is the basin lag:

$t_{\text {lag }}=\frac{\left(L^{0.8} \times\left(\frac{1000}{C N}-10+1\right)^{0.7}\right)}{\left(1900 Y^{0.5}\right)}$

where $L$ is the flow length (feet), $C N$ is the average curve number, and $Y$ is the average slope gradient (\%) of the basin.

\subsection{Baseflow: The Recession Model}

The recession model adopted in this study is used to explain the drainage process from natural storage in a watershed. Defining the baseflow parameter in flood studies is crucial because it defines the minimum river depth at which additional runoff accumulates. The relationship between baseflow $Q_{t}$ at any time $t$ to an initial value $Q_{0}$ can be expressed as follows (Feldman 2000):

$Q_{t}=Q_{0} k^{t}$

where $Q_{0}$ is the initial baseflow ( $\left.t=0\right)$ and $k$ is an exponential recession constant. The threshold flow, which occurs after the overland peak flood flow, should be specified as a flow rate to the computed peak flood flow when the recession model is applied (Verma et al. 2010).

\subsection{Channel Routing: The Muskingum Model}

The Muskingum model (Feldman 2000) is used for channel flood routing. The primary parameters in the method are $K$ and $X$, which can be estimated using the following equations: 
$K=\frac{L}{V_{w}}$

$X=\frac{1}{2}\left(1-\frac{Q_{0}}{B S_{0} c \Delta x}\right)$

where $K$ is the travel time, $L$ is the distance between the inflow and outflow sections, $V_{w}$ is the flood wave velocity, $X$ is a dimensionless weight $(0 \leq X \leq 0.5), Q_{0}$ is the reference flow from the inflow hydrograph, $B$ is the top width of the flow area, $S_{0}$ is the friction slope or bed slope, $c$ is the flood wave speed (celerity), and $\Delta x$ is the length of the river reach.

\subsection{Model Calibration and Validation}

Uncertainties derived from parameter determination always exist in hydrological modeling, thus the estimation of parameters should be treated with great caution. Model calibration and validation are the two important processes that can reduce uncertainties in parameters. The hydrological simulation in this study demonstrated that peak flood flow and flood volume were sensitive to initial loss abstraction $\left(I_{a}\right)$, lag time $\left(t_{\text {lag }}\right)$, recession constant $(k)$, flood travel time $(K)$, and Muskingum weighting factor $(X)$, and they were often selected for calibrating the HEC-HMS model (Du et al. 2012). The objective of model calibration was to find the best set of parameter values that produce a best fit between model and observations. The calibration and validation of the HEC-HMS model was conducted with a split sample procedure and streamflow observation records collected at the outlet of the watershed. The model was run for a period of 6 years (2007-2012), using the years from 2007-2010 as a calibration period. The remaining 2 years (2011-2012) were used to validate the model. In this work, flood events with peak discharge greater than $10,000 \mathrm{~m}^{3} / \mathrm{s}$ are defined as large floods. A total of seven large flood events and four relatively small flood events from 2007-2012-eight for the calibration period and three for the validation period-were obtained to calibrate and validate the HEC-HMS model.

Three evaluation criteria were used in this study to assess model performance: correlation coefficient $\left(R^{2}\right)$, percent errors (PEs) of the peak flood flow and flood volume, and Nash-Sutcliffe model efficiency $(E)$ (Nash and Sutcliffe 1970). The $R^{2}$ value indicates the correlation between the observed and simulated values, and it is calculated using Eq. 10. $R^{2}$ ranges from 1.0 (best) to 0.0 (unacceptable). The $E$ value measures how well a plot of simulated flows fits the observed data, and it is calculated using Eq. 11. If the $E$ value is less than or approximately zero, the model simulation is unacceptable. The best value is 1 .
$R^{2}=\frac{\sum\left(Q_{0}(i)-Q_{0, \text { mean }}\right) \times\left(Q_{s}(i)-Q_{s, \text { mean }}\right)}{\sqrt{\sum\left(Q_{0}(i)-Q_{0, \text { mean }}\right)^{2} \times\left(Q_{s}(i)-Q_{s, \text { mean }}\right)^{2}}}$

$E=1-\frac{\sum\left(Q_{s}(i)-Q_{0}(i)\right)^{2}}{\sum\left(Q_{0}(i)-Q_{0, \text { mean }}\right)^{2}}$

where $Q_{s}$ is the simulated peak flood flow $\left(\mathrm{m}^{3} / \mathrm{s}\right)$ or flood volume $(\mathrm{mm})^{6}$ value, $Q_{\mathrm{o}}$ is the observed peak flood flow or flood volume value, $Q_{s \text {,mean }}$ is the average simulated value, and $Q_{\mathrm{o} \text {,mean }}$ is the average observed value.

The peak flood flow and flood volume are important factors used to evaluate system performance. $P E$ is used and defined as shown in Eq. 12. A value of approximately 0 is an optimal $P E$. In addition, a negative value indicates model overestimation, and a positive value indicates model underestimation.

$P E=\frac{Q_{s}-Q_{0}}{Q_{0}} \times 100$.

\section{Results}

This section first presents model calibration and validation results of the HEC-HMS model, then characterizes land use/land cover changes and urbanization in the study region, and presents the results of analysis of the effects of urbanization on flooding.

\subsection{Calibration and Validation of Hydrologic Engineering Center-Hydrologic Modeling System}

The 2010 land use data and precipitation data during 2007-2010 were used to simulate the eight flood events in the calibration period 2007-2010. Figure 2 illustrates the comparison of the observed and simulated flood hydrographs. It demonstrates good agreement between the simulated and the observed hydrographs for all flood events. Table 3 presents the simulated results and evaluation criteria for the 11 flood events for both the calibration and the validation periods. According to Nash and Sutcliffe (1970), when the efficiency (Nash) index value is greater than 0.6, the simulation results are reliable. It can be seen that during the calibration period, the minimum efficiency value is 0.6 . Moreover the efficiency value for events 1,3 , and 5 was greater than 0.8. The mean correlation coefficient was 0.95 , and the correlation coefficient was greater than 0.8 for all flood hydrographs. The $P E$ of the simulated peak flood flow and flood volume was under $20 \%$ for most events, except for Event 8. Flood event 8 was caused by an

\footnotetext{
6 The unit of flood volume is $\mathrm{mm}$, which is the result of dividing the volume $\left(\mathrm{m}^{3}\right)$ by the area of the basin.
} 

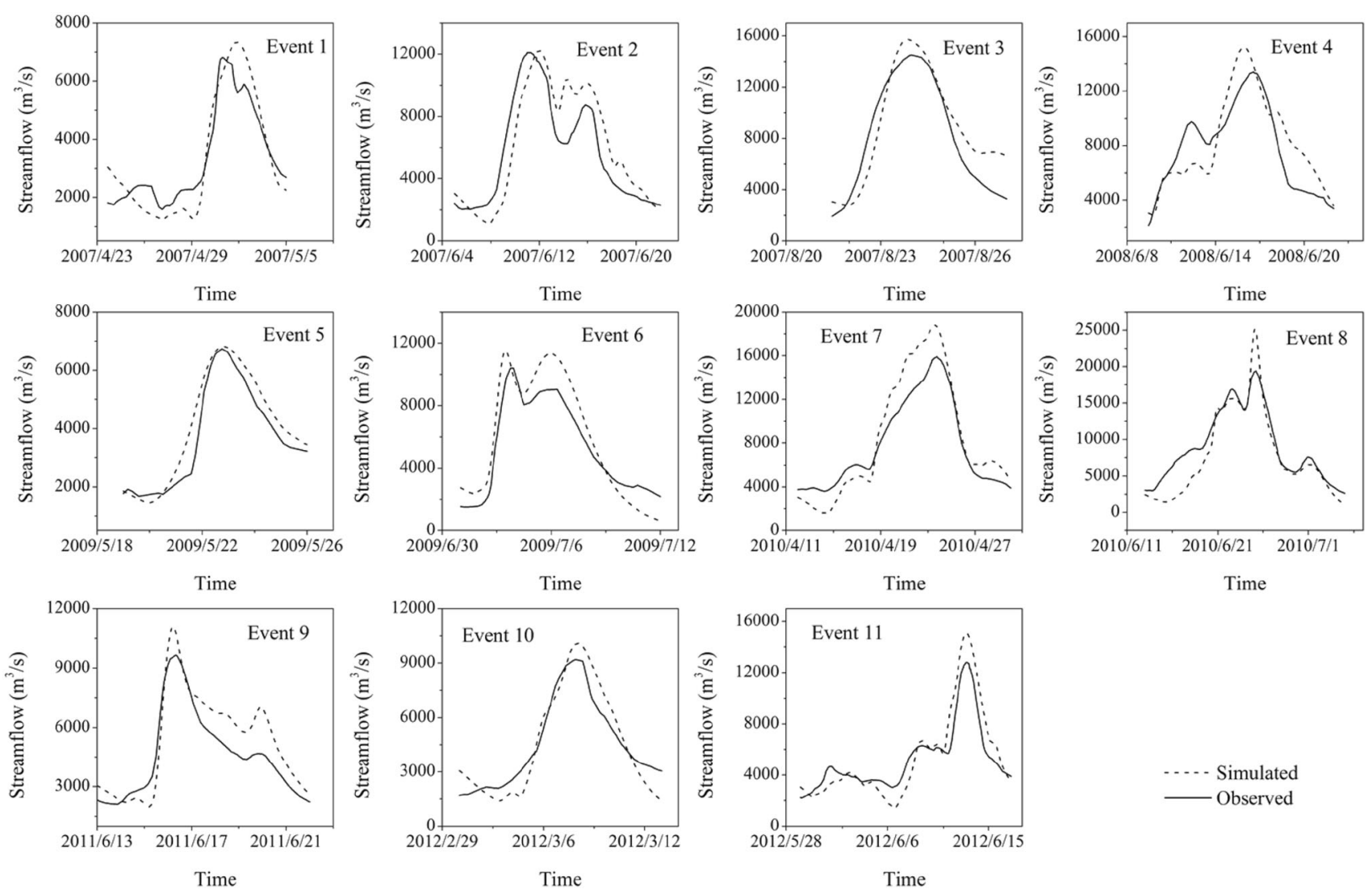

Fig. 2 Comparison of observed and simulated hydrographs for 11 flood events in the Xiang River Basin

Table 3 Summary of peak flood flow and flood volume for 11 flood events during the calibration (2007-2010) and validation (2011-2012) periods in the Xiang River Basin

\begin{tabular}{|c|c|c|c|c|c|c|c|c|c|}
\hline & $\begin{array}{l}\text { Flood } \\
\text { event }\end{array}$ & $\begin{array}{l}\text { Observed peak } \\
\text { flow }\left(\mathrm{m}^{3} / \mathrm{s}\right)\end{array}$ & $\begin{array}{l}\text { Simulated peak } \\
\text { flow }\left(\mathrm{m}^{3} / \mathrm{s}\right)\end{array}$ & $\begin{array}{l}\text { Observed flood } \\
\text { volume }(\mathrm{mm})\end{array}$ & $\begin{array}{l}\text { Simulated flood } \\
\text { volume }(\mathrm{mm})\end{array}$ & $\mathrm{R}^{2}$ & $\mathrm{E}$ & $\mathrm{PE}_{\mathrm{f}}$ & $\mathrm{PE}_{\mathrm{v}}$ \\
\hline \multirow{8}{*}{$\begin{array}{l}\text { Calibration } \\
\text { period }\end{array}$} & 1 & 6818 & 7341 & 40 & 40 & 0.95 & 0.80 & 7.67 & 0.00 \\
\hline & 2 & 12,100 & 12,225 & 101 & 108 & 0.87 & 0.70 & 1.03 & 0.07 \\
\hline & 3 & 14,500 & 15,741 & 49 & 53 & 0.92 & 0.82 & 8.56 & 0.08 \\
\hline & 4 & 13,400 & 15,192 & 103 & 109 & 0.83 & 0.60 & 13.37 & 0.06 \\
\hline & 5 & 6740 & 6810 & 30 & 34 & 0.97 & 0.85 & 1.04 & 0.13 \\
\hline & 6 & 10,400 & 11,507 & 62 & 69 & 0.96 & 0.76 & 10.64 & 0.11 \\
\hline & 7 & 15,900 & 18,812 & 148 & 160 & 0.98 & 0.76 & 18.31 & 0.08 \\
\hline & 8 & 19,400 & 25,356 & 208 & 180 & 0.95 & 0.76 & 30.70 & -0.13 \\
\hline \multirow{4}{*}{$\begin{array}{l}\text { Validation } \\
\text { period }\end{array}$} & 9 & 9650 & 11,178 & 44 & 50 & 0.93 & 0.72 & 15.83 & 0.14 \\
\hline & 10 & 9180 & 10,085 & 58 & 58 & 0.96 & 0.85 & 9.86 & 0.00 \\
\hline & 11 & 12,800 & 15,083 & 103 & 107 & 0.96 & 0.74 & 17.84 & 0.04 \\
\hline & \multicolumn{5}{|l|}{ Average } & 0.94 & 0.76 & 12.26 & 0.05 \\
\hline
\end{tabular}

extreme rainstorm event that has rarely occurred in the history of the study region. The low performance of the model at simulating peak flood flow of event 8 could be attributed to limitation of the HEC-HMS in simulating such a massive flood event. But even so, the general shape of the hydrograph has been accurately depicted except for the overestimation in the peak flood flow.

Parameters determined during calibration were used without alterations in the validation period and three flood events in 2011 and 2012 were used to validate the model. The Nash efficiency value of flood Events 9, 10, and 11 
were higher than 0.7 . The total mean efficiency was 0.76 and the evaluation results show that the model performance was satisfactory for both calibration and validation periods. It indicates that the selected methods in the HEC-HMS during each hydrologic process were applicable for flood event simulation in the Xiang River Basin.

\subsection{Land Use and Land Cover Changes and Urbanization in the Xiang River Basin}

The LULC changes and urbanization in the Xiang River Basin (XRB) feature noticeable spatial differences based on topography. In the upper XRB, which is predominantly mountainous, the economic activities largely involve agriculture, and the urbanization level there is relatively low, with a central urban area located in Yongzhou City. In the middle XRB, where hills and valley plains are dominant, the economic sectors largely consist of industry and mining. The urbanization level is relatively high, and the central urban area is located in Hengyang City. In the lower $\mathrm{XRB}$, which mainly features valley plains, the economic sectors largely consist of industry and service industries, and the urbanization level is very high, with a central urban area located in Zhuzhou City. The National Plan for Main Functional Areas, promulgated by the State Council of China in 2010, listed the middle reaches of the Yangtze River, including the Changsha-Zhuzhou-Xiangtan Metropolitan Agglomerations, Wuhan City Circle, and Poyang Lake Ecological and Economic Zone, as national key development areas. In the Twelfth Five-Year Plan, the Chinese government proposed to promote growth in the central regions vigorously, with a focus on promoting development around the Changsha-Zhuzhou-Xiangtan Metropolitan Agglomerations. A series of related national and regional policies has provided a good external environment for developing the metropolitan areas in the XRB, and urban expansion has become increasingly intense.

To analyze the urban expansion patterns of different subcatchments in the upper, the middle, and the lower XRB from the 1980s to 2015, we selected three subcatchments closest to the central urban areas, namely, the UpYong, MidHeng and DownZhu catchments, which are closest to Yongzhou, Hengyang, and Zhuzhou Cities, respectively. Figure 3 shows the spatiotemporal patterns of land use changes in the UpYong, MidHeng, and DownZhu catchments in the upper, the middle, and the lower XRB respectively. The major LULC classes in the UpYong catchment were cultivated land, forest, and grassland, whereas the major LULC classes in the MidHeng and DownZhu catchments were forest, cultivated land, and artificial surfaces. Compared to that in the 1980s, the percentage of artificial surface area in 2005 increased by 7.1, 8.9, and $11.9 \%$ in the UpYong, MidHeng, and DownZhu catchments, and the total artificial surface area increased by $13.5,9.5$, and $27.9 \mathrm{~km}^{2}$ respectively. By contrast, the proportion of cultivated land significantly decreased. The conversion of cultivated lands to artificial surfaces was the major change. From the 1980s to 2005, the urbanization process was slow in the XRB, and urban expansion predominantly occurred in transitional zones between artificial surface areas and cultivated lands. In 2005-2015, however, the XRB experienced rapid urban development. In the lower reach of the basin, Changsha-Zhuzhou-Xiangtan Metropolitan Agglomerations exhibited rapid growth both in quantity and scale of built-up areas. The urbanization rate reached $66 \%$ in 2014 , which was $15 \%$ higher than the average rate in Hunan Province. The artificial surface area in the DownZhu catchment increased from 59.4 to $186.0 \mathrm{~km}^{2}$, with a total of $126.6 \mathrm{~km}^{2}$ increase over the course of 10 years. This trend reflects the increasing demand for urbanization. The urban spatial structure of the DownZhu catchment began to change from a single center to multiple centers. Additionally, some isolated urbanized patches in urban fringe areas gradually merged into large patches and formed new cores of artificial surface growth.

\subsection{Effects of Urbanization on Flooding in the Xiang River Basin}

The rainfall-runoff process is the result of a combination of climatic and underlying surface conditions. Urbanization leads to the continuous expansion of impervious surface areas, hinders the infiltration of water and changes the underlying surface characteristics, which ultimately influences the peak flood flow and flood volume (Huang et al. 2008; Lei et al. 2016). We applied the calibrated HECHMS model in the XRB to simulate the flood responses to urban expansion in three ungauged subcatchments based on the principle of similarity by spatial proximity. The study was conducted to simulate the peak flood flow and flood volume at the subcatchment outlets at an hourly temporal step using the constant precipitation data in June 2010, at the time that an extreme rainstorm occurred in the whole basin, and different land use conditions pertained in the 1980s, 2005, and 2015.

To assess the impact of urbanization on floods, the impervious surface ratio and curve number $(C N)$ have been selected to quantify the urbanization level. The impervious surface ratio is the proportion of a lot that is covered by impenetrable materials, such as concrete. The $C N$ value is an empirical parameter based on the area's hydrologic soil group, land use, and watershed moisture conditions, which indicates the ability to generate runoff. Table 4 illustrates the simulated results of peak flood flow and flood volume at different urbanization levels in the UpYong, MidHeng, and DownZhu catchments. From the 1980s-2005, the 


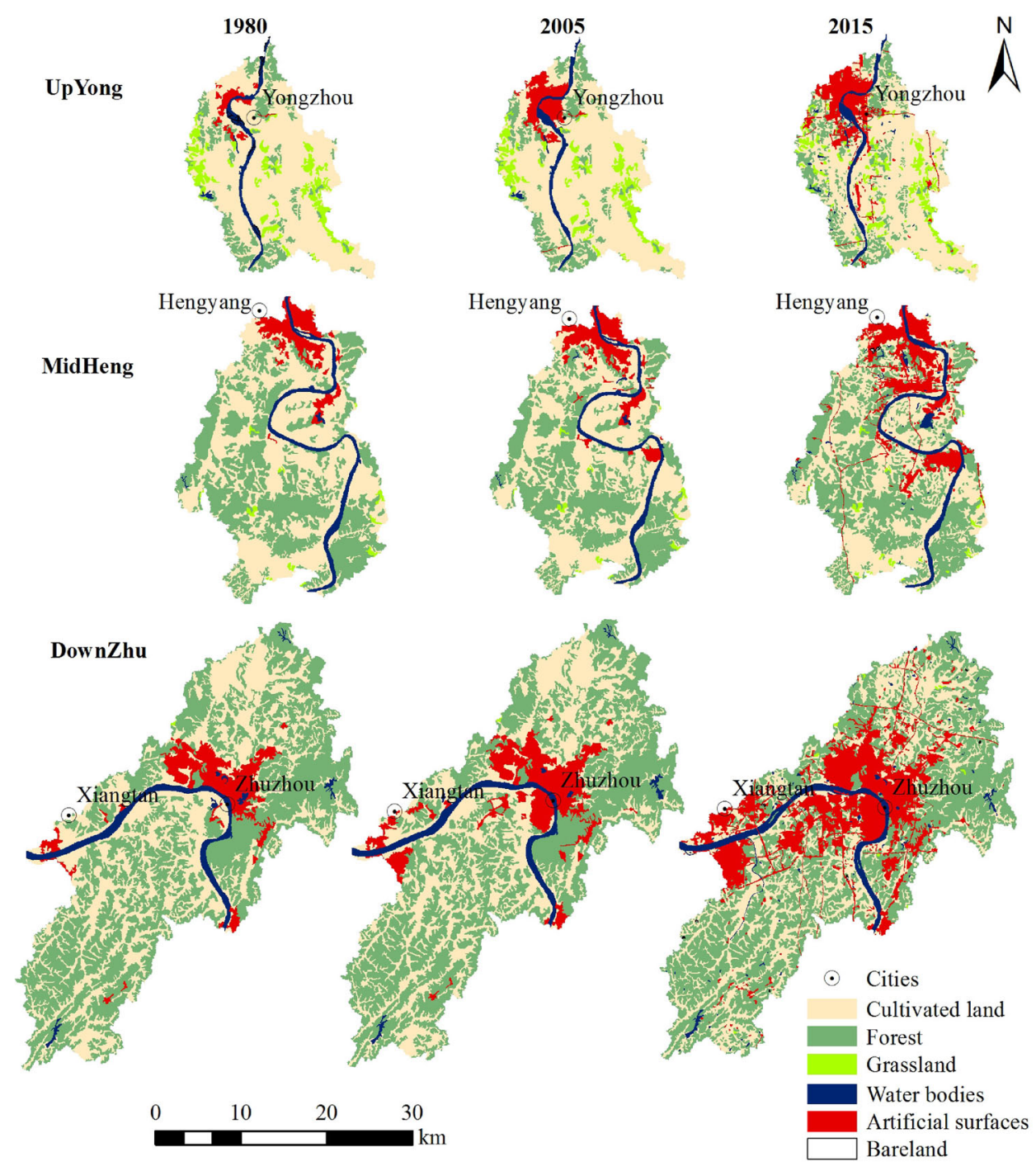

Fig. 3 LULC changes in the UpYong, MidHeng and DownZhu catchments from the 1980s to 2015

Table 4 Responses of the peak flood flow and flood volume to land use changes and urbanization in the UpYong, MidHeng, and DownZhu catchments of the Xiang River Basin

\begin{tabular}{|c|c|c|c|c|c|c|c|}
\hline Catchments & Land use conditions & Impervious ratio (\%) & Curve number & $Q_{p}$ & $R a \_p$ & $Q_{v}$ & $R a_{-} v$ \\
\hline \multirow[t]{3}{*}{ UpYong } & $1980 \mathrm{~s}$ & 5.7 & 74.9 & 138.6 & 0 & 43.8 & 0 \\
\hline & 2005 & 9.1 & 75.5 & 145.4 & 4.9 & 46.2 & 5.5 \\
\hline & 2015 & 13.5 & 75.6 & 150.6 & 8.7 & 48.4 & 10.5 \\
\hline \multirow[t]{3}{*}{ MidHeng } & $1980 \mathrm{~s}$ & 7.7 & 72.8 & 370.4 & 0 & 66.2 & 0 \\
\hline & 2005 & 9.1 & 73.0 & 380.0 & 2.6 & 67.4 & 1.8 \\
\hline & 2015 & 13.8 & 73.8 & 410.6 & 10.9 & 71.2 & 7.6 \\
\hline \multirow[t]{3}{*}{ DownZhu } & $1980 \mathrm{~s}$ & 8.0 & 73.2 & 1208.6 & 0 & 110.4 & 0 \\
\hline & 2005 & 10.5 & 73.7 & 1240.6 & 2.7 & 113.2 & 2.5 \\
\hline & 2015 & 19.1 & 75.6 & 1354.4 & 12.1 & 123.2 & 11.6 \\
\hline
\end{tabular}

$Q_{p}=$ simulated peak flood flow $\left(\mathrm{m}^{3} / \mathrm{s}\right) ; R a_{\_} p=Q_{p}$ increase from the $1980 \mathrm{~s}(\%) ; Q_{v}=$ simulated flood volume (mm); $R a_{-} v=Q_{v}$ increase from the $1980 \mathrm{~s}(\%)$ 

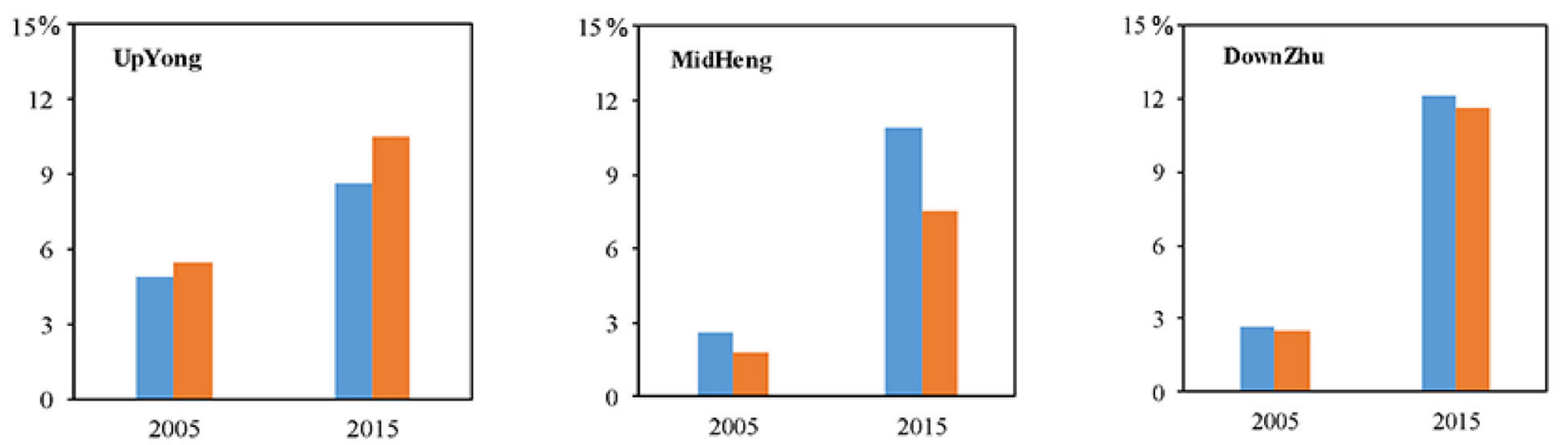

- Simulated peak flow increase from the land use condition of the $1980 \mathrm{~s}$ - Simulated flood volume increase from the land use condition of the $1980 \mathrm{~s}$

Fig. 4 Peak flood flow and flood volume increases based on the land use conditions in 2005 and 2015 compared to those in the 1980s in the UpYong, MidHeng, and DownZhu catchments of the Xiang River Basin

urbanization process was slow, and the impervious surface areas of the three subcatchments increased by 10.8, 7.7, and $23.3 \mathrm{~km}^{2}$. But the urbanization process has been accelerated since 2005, and the impervious surface areas of the three subcatchments expanded by $14.0,25.7$, and $80.0 \mathrm{~km}^{2}$ from 2005 to 2015 , with growth rates of 48.4 , 51.6, and $81.9 \%$. Additionally, an increasing trend was observed from the upstream to the downstream areas. The $C N$ value displayed a similar trend, increasing by $0.1,0.8$, and 1.9 , and the growth rates were $0.1,1.1$, and $2.6 \%$ in UpYong, MidHeng, and DownZhu catchments, respectively, between 2005 and 2015. Land use changes from the 1980 s to 2005 caused $4.9,2.6$, and $2.7 \%$ increases in the peak flood flow in the three subcatchments, and the flood volume exhibited a similar trend. With a low urbanization rate from the 1980s to 2005, the impact of urban expansion on the flood discharge in these catchments presented no obvious spatial variation.

The land use changes that took place from the 1980s to 2015 were very significant, however, causing 8.7, 10.9, and $12.1 \%$ increases in the peak flood flow and 10.5, 7.6, and $11.6 \%$ increases in flood volume in the three subcatchments. Moreover, the growth rate of peak discharge gradually increased from upstream to downstream. The change in the peak flood flow exhibited a spatial variation that was consistent with those of the impervious surface ratio and $C N$ value in the basin. Thus, intensified urbanization could result in further increases in peak flood flow and flood volume in the basin in the near future. Meanwhile, due to the accumulative effects of flood flow from the upper to the lower XRB, together with urbanization-induced intensification of flood processes, higher flood hazard risks can be expected in the middle and lower XRB in particular. How to enhance mitigation of flood disasters in a changing environment, particularly considering impacts of urbanization on flood processes, is crucial in the management of land use and urbanization.

\section{Discussions}

The findings of this study suggest that general increases in urbanization and land use change increased peak flood flow and flood volume in the XRB and its three subcatchments. But by comparing LULC changes and peak flood flow and flood volume at the subcatchment scale, we found that the relationship between urban landscape change and flow change is complex; notably, the impact of urbanization on peak flood flow and flood volume varied in different subcatchments. In the UpYong catchment, the urbanization process presented a higher contribution to flood volume than peak flood flow, whereas in the MidHeng and DownZhu catchments, the urbanization process was associated with a lower impact on change in flood volume than peak flood flow (Fig. 4). These findings indicate the complex effects of land use change on flood response at subcatchment scale. The response of flood discharge to land use change and urbanization was influenced by multiple factors, such as the characteristics of the underlying surface, the pattern of land use conversion in catchments, and the nature of precipitation events.

The natural geomorphological setting of the catchment, such as drainage area, shape, and slope, may also play vital roles in the causal relationship between LULC changes in a subcatchment and the peak flood flow at the catchment outlet (Kim and Lee 2014; Sanyal et al. 2014). Our results show an increased intensity of urbanization from the upper to the lower XRB, corresponding to an increase of the drainage areas and slopes of the UpYong, MidHeng, and DownZhu catchments-the drainage areas are 318, 547, and $930 \mathrm{~km}^{2}$, and the mean catchment slopes are 5.2, 5.7, and $6.4 \%$, respectively. The catchment shape and hydrological character of a drainage basin can be reflected through the elongation ratio (Kim and Lee 2014), which indicates the degree of the strip-like extension of the catchment-the higher the elongation ratio, the longer and 
Fig. 5 Proportions of LULC classes in the UpYong (a), MidHeng (b), and DownZhu (c) catchments in the $1980 \mathrm{~s}$ (left) and 2015 (right) (a)
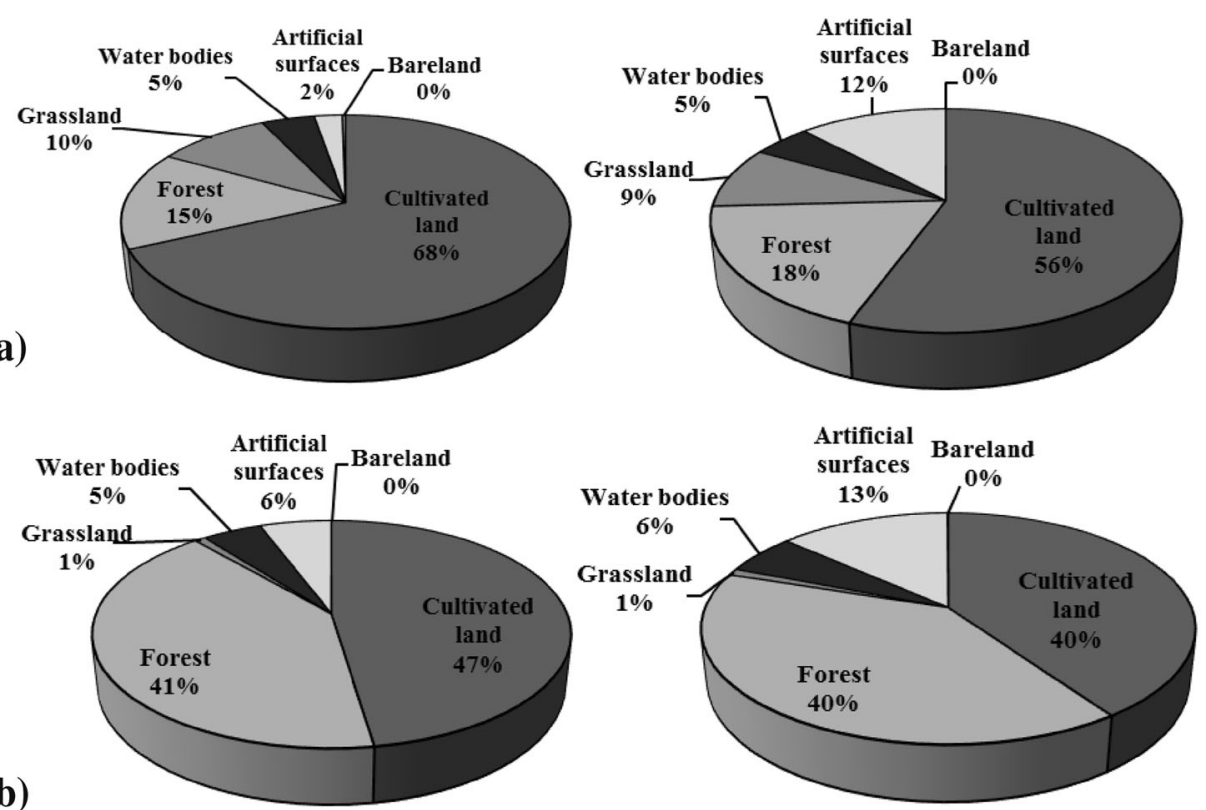

(c)
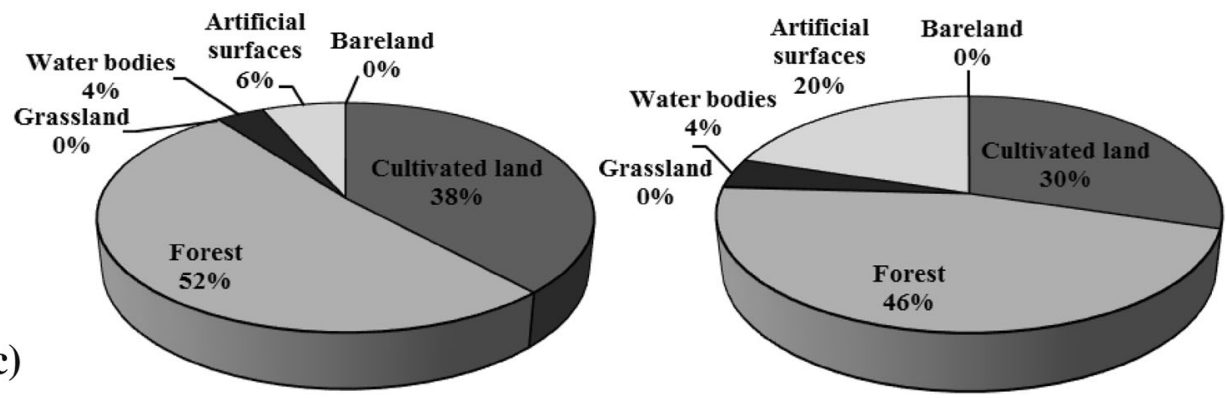

narrower the catchment shape. The elongation values for the UpYong and MidHeng catchments are 1.5 and 1.4, but the DownZhu catchment had a higher elongation ratio of 2.4. It reveals that for the longer, narrower and steeper catchments, peak flood flow seems to be more susceptible to precipitation changes than flood volume upon changes. Catchment attributes and land use changes may partially explain why different LULC and urbanization trends in different subcatchments had varying impacts on the peak flood flow and flood volume at the catchment outlets.

Significant differences were observed in the proportions of LULC classes in the three subcatchments between the 1980s and 2015 (Fig. 5). The land use in the UpYong catchment was dominated by cultivated land, which accounted for more than $50 \%$ of the catchment area. Forest and cultivated land were the two main land use types in the MidHeng catchment, and they both constituted $40 \%$ or more of the catchment area. In the DownZhu catchment, forest had the largest proportion among the land use types, which took more than $45 \%$ of the total area. The main LULC changes across the subcatchments varied considerably. These changes were primarily observed in the UpYong and MidHeng catchments, where about 12 and 7\% of cultivated lands were transformed to other uses from the 1980s to 2015 and artificial surfaces increased by about 10 and $7 \%$, but there were little change in forest areas (Figs. 5a, b). In the DownZhu catchment, $8 \%$ of cultivated land and $6 \%$ of forest were transformed to artificial surfaces. The diverse patterns of land use conversion have various effects on peak flood flow and flood volume. Peak flood flow is more susceptible to the conversation of forest to artificial surface (Fig. 5c), and flood volume shows significant change with the transformation of cultivated land to artificial surface. Thus, these factors exert complex influences on the flood response of a catchment.

In this study, we investigated flood responses to land use change and urbanization in different subcatchments of the XRB. However, climate change is another important factor that influences flood risks. In addition, a close and complex relationship exists between land use change and climate change (Tu 2009; Karlsson et al. 2016; Yan et al. 2016). The link between climate fluctuations/change and land use change is an extremely important layer of complexity in managing flooding in a catchment. The combined impacts of climate change and land use changes on flood disasters were not explored in this article. Because of the potential 
impacts of enhanced flooding on future flood disasters, more in-depth analysis is needed. Such analysis could prevent the overestimation or underestimation of the impact of land use change.

\section{Conclusion}

Characteristics of the underlying surface and conversion patterns of LULC classes in catchments can affect flood runoff process. Studies of the response of peak flood flow and flood volume to urbanization at the outlets of different subcatchments are of great significance for land use planning and hydrological management in a basin. This article has attempted to utilize GIS, remote sensing data, and hydrological models as tools for assessing the effects of different degrees of urbanization on flooding. The case study was conducted in three subcatchments distributed in the upper, middle, and lower reaches of the Xiang River Basin. The following conclusions can be drawn from this study:

(1) The proportion of artificial surfaces in the XRB was characterized by spatial variations that gradually increased from upstream to downstream. Urban expansion was relatively prominent in the MidHeng and DownZhu catchments, where the proportion of artificial surfaces reached $13.3 \%$ and $20.0 \%$, respectively, in 2015. Additionally, the urban spatial structure in these catchments began to shift from a single urban center to multiple centers;

(2) Both peak flood flow and flood volume increased with intensified urbanization, and the most significant change was observed in the downstream subcatchment. With the changes in land use and urbanization from the 1980s to 2015, the peak flood flows in the UpYong, MidHeng, and DownZhu catchments increased by $12.0,40.2$, and $145.8 \mathrm{~m}^{3} / \mathrm{s}$, with growth rates of $8.7,10.9$, and $12.1 \%$, respectively. The growth rate of peak flood flow displayed spatial variations that gradually increased from upstream to downstream, and these variations were consistent with changes in the impervious surface ratio and $\mathrm{CN}$ value. Due to accumulative effects of flood flow from the upper to the lower XRB together with urbanization-induced intensification of flood processes, higher risks of flood hazard can be expected in the middle and in the lower XRB in particular; and

(3) The effects of urbanization on peak flood flow and flood volume varied in subcatchments with different underlying surface conditions. In the UpYong catchment, the effect of urbanization on the flood volume was greater than that on the peak flood flow. In the
MidHeng and DownZhu catchments, however, the impact of urbanization was greater for peak flood flow than for the flood volume. These results are associated with differences in the characteristics of the underlying surface, the proportions of LULC classes, and the conversion of land use in the catchments from field and forest to more impervious urban surfaces.

In recent decades, the $\mathrm{XRB}$ has experienced rapid urbanization, with an increase in peak flood flow and increased frequency of floods. Balancing urban development and flood risk reduction is a dilemma faced by the region's decision makers. The results of this study reveal the relationship of urbanization and flood risks from the upper to the lower XRB, which provides a scientific foundation for flood risk mitigation planning and management in the area. Our study can assist decision makers to better understand the circumstances and impacts of these changes and to implement comprehensive, locally specific, integrated, and balanced solutions in regional planning and flood risk management.

Acknowledgements This study was supported by the Open Fund of State Key Laboratory of Remote Sensing Science (Grant No. OFSLRSS201720), the National Natural Science Foundation of China (Grant No. 41401097; 41771536), and National Key Research and Development Program Project: Development of the Platform for Dynamic Early Warning and Risk Assessment of Mountain Torrents Disaster (2017YFC1502505). The authors are grateful for the data provided by the China Meteorological Data Sharing Service System and the Hunan Hydrology and Water Resource Authority. Last but not the least, our cordial gratitude should be extended to the editor, Dr. Ying $\mathrm{Li}$, and anonymous reviewers for their professional and pertinent comments and revision suggestions that are greatly helpful for further quality improvement of this manuscript.

Open Access This article is distributed under the terms of the Creative Commons Attribution 4.0 International License (http://crea tivecommons.org/licenses/by/4.0/), which permits unrestricted use, distribution, and reproduction in any medium, provided you give appropriate credit to the original author(s) and the source, provide a link to the Creative Commons license, and indicate if changes were made.

\section{References}

Abdellatif, M., W. Atherton, R. Alkhaddar, and Y. Osman. 2015. Flood risk assessment for urban water system in a changing climate using artificial neural network. Natural Hazards 79(2): 1059-1077.

Aerts, J.C., W.W. Botzen, K. Emanuel, N. Lin, H. de Moel, and E.O. Michel-Kerjan. 2014. Evaluating flood resilience strategies for coastal megacities. Science 344(6183): 473-475.

Akter, A., and S. Ahmed. 2015. Potentiality of rainwater harvesting for an urban community in Bangladesh. Journal of Hydrology 528: 84-93.

Brakensiek, D.L., and W.J. Rawls. 1983. Green-Ampt infiltration model parameters for hydrologic classification of soils. In Proceedings of the specialty conference on advances in 
irrigation and drainage: Surviving external pressures, 20-22 July 1983, Jackson, Wyoming, USA, 558.

Cronshey, R., 1986. Urban hydrology for small watersheds. Technical release 55 (TR-55). Washington, DC: U.S. Department of Agriculture, Soil Conservation Service, Engineering Division. https://www.nrcs.usda.gov/Internet/FSE_DOCUMENTS/ stelprdb1044171.pdf. Accessed 26 Oct 2018.

Du, J. 2010. Integrated flood risk assessment and risk governance in Hunan province. Ph.D thesis. Beijing: Beijing Normal University (in Chinese).

Du, J., L. Qian, H. Rui, T. Zuo, D. Zheng, Y. Xu, and C.-Y. Xu. 2012. Assessing the effects of urbanization on annual runoff and flood events using an integrated hydrological modeling system for Qinhuai River basin, China. Journal of Hydrology 464-465: 127-139.

Du, S., P. Shi, A. Van Rompaey, and J. Wen. 2015. Quantifying the impact of impervious surface location on flood peak discharge in urban areas. Natural Hazards 76(3): 1457-1471.

Elliott, A.H., and S.A. Trowsdale. 2007. A review of models for low impact urban stormwater drainage. Environmental Modelling \& Software 22(3): 394-405.

Feldman, A.D. 2000. Hydrologic modeling system HEC-HMS: Technical reference manual. Davis, CA: U.S. Army Corps of Engineers, Hydrologic Engineering Center.

Halwatura, D., and M.M.M. Najim. 2013. Application of the HECHMS model for runoff simulation in a tropical catchment. Environmental Modelling \& Software 46: 155-162.

Huang, S., S. Cheng, J. Wen, and J. Lee. 2008. Identifying peakimperviousness-recurrence relationships on a growing-impervious watershed, Taiwan. Journal of hydrology 362(3-4): 320-336.

Karlsson, I.B., T.O. Sonnenborg, J.C. Refsgaard, D. Trolle, C.D. Børgesen, J.E. Olesen, E. Jeppesen, and K.H. Jensen. 2016. Combined effects of climate models, hydrological model structures and land use scenarios on hydrological impacts of climate change. Journal of Hydrology 535: 301-317.

Kim, H.S., and S. Lee. 2014. Assessment of the adequacy of the regional relationships between catchment attributes and catchment response dynamics, calibrated by a multi-objective approach. Hydrological Processes 28(13): 4023-4041.

Lei, C., Y. Xu, Q. Zhang,Y. Wang, and G. Li. 2016. Impacts of landuse change on flood process and frequency of various return periods: A case study of Jiaokou Reservoir watershed in Fenghua Rive. Acta Ecologica Sinica 36(16): 5017-5026.

Li, J.F., Y.D. Chen, L. Zhang, Q. Zhang, and F.H.S. Chiew. 2016. Future changes in floods and water availability across China: Linkage with changing climate and uncertainties. Journal of Hydrometeorology 17(4): 1295-1314.

Liu, Y., X. Zeng, L. Xu, D. Tian, G. Zeng, X. Hu, and Y. Tang. 2011. Impacts of land-use change on ecosystem service value in Changsha, China. Journal of Central South University of Technology 18(2): 420-428 (in Chinese).

Luo, Q., Y. Li, K. Wang, and J. Wu. 2013. Application of the SWAT model to the Xiangjiang river watershed in subtropical central China. Water Science \& Technology 67(9): 2110-2116.

Miller, J.D., H. Kim, T.R. Kjeldsen, J. Packman, S. Grebby, and R. Dearden. 2014. Assessing the impact of urbanization on storm runoff in a peri-urban catchment using historical change in impervious cover. Journal of Hydrology 515: 59-70.

Muis, S., B. Güneralp, B. Jongman, J.C.J.H. Aerts, and P.J. Ward. 2015. Flood risk and adaptation strategies under climate change and urban expansion: A probabilistic analysis using global data. Science of Total Environment 538: 445-457.

Nash, J.E., and J.V. Sutcliffe. 1970. River flow forecasting through conceptual models part I - A discussion of principles. Journal of hydrology 10(3): 282-290.
Pathirana, A., H.B. Denekew, W. Veerbeek, C. Zevenbergen, and A.T. Banda. 2014. Impact of urban growth-driven landuse change on microclimate and extreme precipitation-A sensitivity study. Atmospheric Research 138: 59-72.

Ren, G., Y. Zhou, Z. Chu, J. Zhou, A. Zhang, J. Guo, and X. Liu. 2008. Urbanization effects on observed surface air temperature trends in north China. Journal of Climate 21(6): 1333-1348.

Sanyal, J., A.L. Densmore, and P. Carbonneau. 2014. Analysing the effect of land-use/cover changes at sub-catchment levels on downstream flood peaks: A semi-distributed modelling approach with sparse data. Catena 118: 28-40.

Sheng, J., and J.P. Wilson. 2009. Watershed urbanization and changing flood behavior across the Los Angeles metropolitan region. Natural Hazards 48(1): 41-57.

Shuster, W.D., J. Bonta, H. Thurston, E. Warnemuende, and D.R. Smith. 2005. Impacts of impervious surface on watershed hydrology: A review. Urban Water Journal 2(4): 263-275.

Suriya, S., and B.V. Mudgal. 2012. Impact of urbanization on flooding: The Thirusoolam sub watershed-A case study. Journal of Hydrology 412-413: 210-219.

Tripathi, R., S.K. Sengupta, A. Patra, H. Chang, and I.W. Jung. 2014. Climate change, urban development, and community perception of an extreme flood: A case study of Vernonia, Oregon, USA. Applied Geography 46: 137-146.

$\mathrm{Tu}$, J. 2009. Combined impact of climate and land use changes on streamflow and water quality in eastern Massachusetts, USA. Journal of Hydrology 379(3-4): 268-283.

United Nations, Department of Economic and Social Affairs, Population Division. 2011. World population prospects: The 2010 revision. Volume I: Comprehensive tables, ST/ESA/SER.A/ 313. http://www.un.org/en/development/desa/population/publica tions/pdf/trends/WPP2010/WPP2010_Volume-I_Comprehen sive-Tables.pdf. Accessed 7 Nov 2018.

USDA (United States Department of Agriculture). 2004. Estimation of direct runoff from storm rainfall. Washington, DC: United States Department of Agriculture.

Verma, A.K., M.K. Jha, and R.K. Mahana. 2010. Evaluation of HECHMS and WEPP for simulating watershed runoff using remote sensing and geographical information system. Paddy Water Environment 8(2): 131-144.

Wang, L., Z. Guo, X. Xiao, T. Chen, X. Liao, J. Song, and B. Wu. 2008. Heavy metal pollution of soils and vegetables in the midstream and downstream of the Xiangjiang River, Hunan Province. Journal of Geographical Sciences 18(3): 353-362.

Warburton, M.L., R.E. Schulze, and G.P.W. Jewitt. 2012. Hydrological impacts of land use change in three diverse South African catchments. Journal of Hydrology 414-415: 118-135.

Wu, C., A.T. Murray. 2003. Estimating impervious surface distribution by spectral mixture analysis. Remote Sensing of Environment 84(4): 493-505.

Yan, R., J. Huang, Y. Wang, J. Gao, and L. Qi. 2016. Modeling the combined impact of future climate and land use changes on streamflow of Xinjiang Basin, China. Hydrology Research 47(2): $356-372$

Yin, J., D. Yu, Z. Yin, M. Liu, and Q. He. 2016. Evaluating the impact and risk of pluvial flash flood on intra-urban road network: A case study in the city center of Shanghai, China. Journal of Hydrology 537: 138-145.

Yuan, Y. 2003. The study of land use change and its ecological response mechanism in Shenzhen. Ph.D thesis. Beijing: Beijing Normal University (in Chinese).

Zhang, S., Y. Guo, and Z. Wang. 2015. Correlation between flood frequency and geomorphologic complexity of rivers network-A case study of Hangzhou China. Journal of Hydrology 527: 113-118. 
Zhong, S., Y. Qian, C. Zhao, R. Leung, and X.-Q. Yang. 2015. A case study of urbanization impact on summer precipitation in the Greater Beijing Metropolitan Area: Urban heat island versus aerosol effects. Journal of Geophysical Research: Atmospheres 120(20): 10903-10914.

Zhou, F., Y. Xu, Y. Chen, C.-Y. Xu, Y. Gao, and J. Du. 2013. Hydrological response to urbanization at different spatiotemporal scales simulated by coupling of CLUE-S and the SWAT model in the Yangtze River Delta region. Journal of Hydrology 485: 113-125.
Zhou, Q., G. Leng, and M. Huang. 2018. Impacts of future climate change on urban flood volumes in Hohhot in northern China: Benefits of climate change mitigation and adaptations. Hydrology and Earth System Sciences 22(1): 305-316.

Zope, P.E., T.I. Eldho, and V. Jothiprakash. 2016. Impacts of land use-land cover change and urbanization on flooding: A case study of Oshiwara River Basin in Mumbai, India. Catena 145: 142-154. 